\title{
Heat flux from stagnation-point hydrogen-methane-air flames: experiment and modelling
}

\author{
M. S. Elmnefi ${ }^{1}$, S. Staude ${ }^{2}$, U. Bergmann ${ }^{2}$ \& B. Atakan ${ }^{2}$ \\ ${ }^{1}$ Mechanical Engineering Dept, Faculty of Engineering, \\ University of Benghazi, Libya \\ ${ }^{2}$ Thermodynamics, IVG and CeNIDE, \\ University of Duisburg-Essen, Germany
}

\begin{abstract}
Hydrogen-methane-air flames were studied in stagnation-point geometry. Light induced phosphorescence from thermographic phosphors was used to study the wall temperatures and heat fluxes from nearly one-dimensional flat premixed flames. The studied flames were stoichiometric methane-air flames with $10 \%$, $25 \%, 50 \%$ and $75 \%$ hydrogen as well as a pure hydrogen flame at ambient pressure. The flames were burning in a stagnation-point arrangement against a water cooled plate. The central part of this plate was an alumina ceramic plate coated from both sides with chromium doped alumina (ruby) and excited with a $\mathrm{Nd}$ :YAG laser or a green light emitting diode (LED) array to measure the wall temperature from both sides and thus the heat flux rate from the flame. The cold gas velocity was varied from $0.1 \mathrm{~m} / \mathrm{s}$ to $1.2 \mathrm{~m} / \mathrm{s}$. The measured heat flux rates indicate the change of the flame stabilization mechanism from a burner stabilized to a stagnation plate stabilized flame. Flame temperatures were also measured using OH-LIF.

The results were compared to the modeling results of a one dimensional stagnation-point flow, with a detailed reaction mechanism. This geometry may be well suited for further studies of the elementary flame wall interaction. The flame temperatures modeled were generally around $200 \mathrm{~K}$ lower than those measured.
\end{abstract}

Keywords: heat flux, thermographic phosphors, stagnation-point flow, hydrogen enriched flames, Nd:YAG laser, light emitting diode, OH-LIF, mole fraction. 


\section{Introduction}

The combustion enthalpy release of gas flames are often transferred to surfaces as heat from direct impinging jets. The convective heat transfer rates are high for such a process. Due to this, flame impingement heating is widely used in many industrial applications such as heating and melting of both glass and metal. One dimensional flame impingement is so far mainly studied in relation to diamond CVD, while the heat transfer from such laminar flames was not in the center of interest. Hydrogen enrichment of hydrocarbon fuels is one strategy to reduce the emissions of carbon dioxide from combustion processes. The hydrogen could in principle come from regenerative energy sources, like solar thermal water splitting. However, the amount will probably not be sufficient to replace natural gas totally in the near future. Thus, mixtures of natural gas with hydrogen are of some interest.

Here, the heat transfer from some hydrogen-methane mixtures to plane walls was studied to get some understanding of the role of hydrogen on the heat transfer to walls. Surface temperatures were measured using thermographic phosphors and gas phase temperatures using OH LIF. The heat flux from the nearly one-dimensional flames was also determined. For a single flame jet impinging on a flat surface many studies are available in the literature, where the focus was on heat flux measurements in the radial direction [1-5]. Baukal and Gebhart [6, 7], Viskanta [8, 9] and Chander and Ray [10] mentioned in their review papers that flame impingement heat transfer needs further research because of its vast applications in industrial and domestic heating systems.

Very recently, Remie et al. [11] have presented analytical relations for calculation of heat flux in the hot spot around the stagnation-point for both two-dimensional and axis-symmetric situations of laminar fuel-oxygen flames impinging on a flat plate. The analysis assumes that a plug flow is generated after the flame front. This assumption, however, is not quite appropriate for fuel-air flames [12]. Kleijn [13] presented a numerical study of heat transfer from laminar, premixed methane-air flames impinging on a flat surface at relatively large distances between burner and plate, so that a two dimensional flow pattern arises. He presented streamlines and isotherms for various cases. He also presented a simple model for stagnation-point heat flux in terms of a flame-tip-to-surface distance. However, detailed analysis of how the centerline velocity and temperature as well as the flame length get affected by the plate was not presented. In the combustion literature, there are also studies on the structure of a Bunsen flame (see e.g. [14]).

$\mathrm{OH}$ laser induced fluorescence (LIF) is a commonly used method to determine the temperature in flames (see e.g. $[15,16]$ ) with the advantage of a relatively simple experimental setup. $\mathrm{OH}$ is abundant in the hot zones of the stoichiometric flames investigated here, thus eliminating the need for seeding as would have been necessary for NO-LIF. However, at lower temperatures the concentration of $\mathrm{OH}$ rapidly falls, which makes the evaluation of temperature gradients near walls extremely difficult with $\mathrm{OH}$ LIF. 
Surface temperature measurement is especially crucial for the determination of heat transfer from flames to solid walls. Often temperature is measured by using thermocouples or optical pyrometry. However, these techniques have their limits. Thermocouples need a very good thermal contact, which is difficult to achieve, especially when the temperatures of moving parts (e.g. in machines) have to be measured. In these cases pyrometry would be an alternative, but the emissivity of the monitored surface has to be known, which again is difficult to achieve, especially in processes where the emissivity varies with the time.

Thermographic phosphors, which are materials doped with trace elements that emit light when suitably exited, overcome these mentioned drawbacks and the method becomes a good alternative for surface temperature measurements and has been proven to be useful and accurate for a variety of thermal measurement applications [17-21]. Phosphor thermometry takes advantage of the thermal dependence of the phosphorescence properties, such as intensity, line-width, line position, and decay rate. Usually phosphorescence decay time is the parameter that is measured to determine the temperature. The lifetime analysis overcome drawbacks of intensity based approaches, since the signal intensity is sensitive to non-uniform excitation, laser intensity, surface curvature, and coating thickness [22]. This technique was used in different combustion environments (e.g. see $[20,23])$.

The present work uses phosphor thermometry to study the heat flux of (nearly) one-dimensional flames. The nearly one dimensional character of premixed stagnation flames presents a great advantage for numerical modeling and generally allows an unambiguous comparison between model and experiment. Hydrogen-methane air flames are studied at relatively small distances between burner and surface for different flow velocities. Mixtures of air with, 10, 25, 50 and $75 \%$ hydrogen in methane $\left(\mathrm{CH}_{4}\right)$ (referred to as $10 \% \mathrm{H}_{2}$, $25 \% \mathrm{H}_{2}, 50 \% \mathrm{H}_{2}$, and $75 \%$ hydrogen, respectively) for stoichiometric flames were considered. The heat flux rate was determined from these experiments. The experimental results were compared to modeling results using detailed chemistry.

\section{Phosphorescence analysis}

The temperature measurement method is based on measuring the lifetime of the phosphorescence of an excited inorganic phosphor, after excitation with a light pulse. The lifetime is a function of temperature, thus the temperatures can be extracted from time dependent phosphorescence intensity. The decay time is usually found by fitting a simple exponential function, which describes the signal shape well in the present case:

$$
I=I_{0} \exp ^{(-t / \tau)}
$$

where:

$I=$ phosphorescence light intensity,

$I_{0}=$ Initial phosphorescence light intensity at time $t=0$, 
$t=$ Time since cessation of excitation,

$\tau=$ Phosphorescence decay time.

A flat alumina ceramic plate acting as the stagnation surface was coated on both sides with a well established phosphor, chromium doped aluminum oxide (ruby) (chromium concentration $=1.1 \%$ ). The coating was produced by the sol-gel method, which is relatively simple to apply [24]. The coated plate was annealed in a tube furnace (Carbolite) in order to obtain the stable $\alpha$-phase of alumina. The temperature-dependence of the phosphorescence lifetime was determined for both sides of the ceramic plate. Since the plate itself also showed some temperature dependent phosphorescence, slight deviations from a mono-exponential decay was observed; an algorithm by Brübach et al. [25] was used to handle this situation. The resulting calibration was later used to determine the surface temperature on both sides of the plate. Figure 1 shows the calibration curve where the phosphorescence lifetime ranges from $2.85 \mathrm{~ms}$ at $295 \mathrm{~K}$ to $0.310 \mathrm{~ms}$ at $573 \mathrm{~K}$.

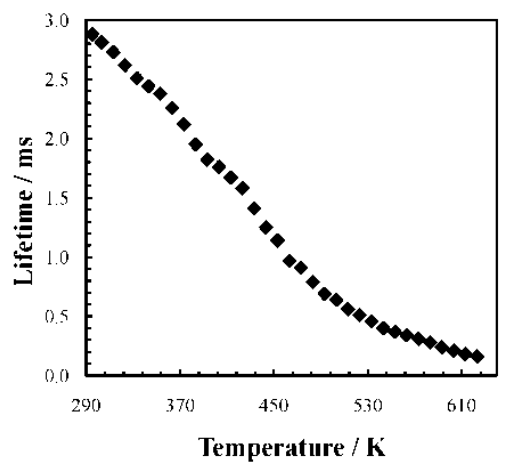

Figure 1: The calibration curve.

The calculated temperature difference between both sides of the plate can be used to determine the heat flux:

$$
\dot{q}=\frac{\dot{Q}}{A}-k \frac{\Delta T}{L}
$$

$\dot{q}=$ Heat flux

$k=$ Thermal conductivity

$\Delta T=$ Temperature difference across the plate

$L=$ Thickness of the plate

$\mathrm{A}=$ Area

$\dot{Q}=$ heat flow rate

This experimental technique is much better suited to obtain the local heat flux rate than measuring the energy balance of the cooling water, since contributions 
of larger radial distances do not disturb the present measurements. Also, the heat flow rate obtained from the energy balance would have to be divided by an area to obtain the heat flux rate. Since the size of the area can be chosen in different ways the results become ambiguous.

\section{Temperature measurement with OH-LIF}

$\mathrm{OH}$ was excited in the A-X 1-0 vibrational band with a Nd:YAG-pumped, frequency-doubled dye laser in the spectral region from 35357 to $35388 \mathrm{~cm}^{-1}$. In this region there are five distinct peaks of the A-X 1-0 band. The relative sizes of the $\mathrm{P}_{21}(5.5)$ and the $\mathrm{Q}_{1}(5.5)$ rotational lines give a good indication of the level of saturation, whilst the three other lines in this spectral range (namely $\mathrm{R}_{1}(14.5)$, $P_{1}(2.5)$ and $R_{2}(12.5)$ ) are very temperature sensitive, since the lines of the $\mathrm{R}$-branch increase in intensity as the temperature increases, whilst the $\mathrm{P}_{1}$ line decreases with increasing temperature.

The laser beam was formed into a laser sheet of about $10 \mathrm{~mm}$ in height and passed through the flame just below the plate. The fluorescence signal was collected at approximately right angles by an intensified CCD camera (PCO) through a UV objective (Nikkon) and a band pass filter (Schott UG11). Within each image was also an area where the laser beam was reflected on the plate some distance from the flame. This region was used as an indication of the laser intensity, so that shot-to-shot variations in the laser strength could be accounted for. The scan was performed in steps of $0.0005 \mathrm{~nm}$; at each wavelength the signal was averaged over 16 shots.

The resulting images were analyzed by pixel row, where one row corresponds to an area of $0.15 \mathrm{~mm}$ in height of the flame. For each vertical position in the flame a spectrum was generated by averaging over the central $4 \mathrm{~mm}$ of the flame region, then subtracting the measured intensity without a laser signal (baseline) and finally dividing by the relative laser intensity for each image. The resulting spectra where then fitted to simulated spectra using the LIF program [26], with temperature, offset, offset ramp, saturation and laser line shape as fit parameters. A typical fit is shown in Figure 2.

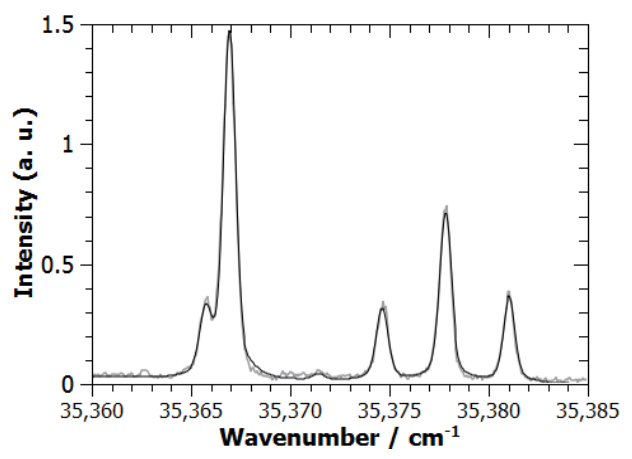

Figure 2: LIF absorption spectrum, measured (grey) and fit (black). 


\section{Experimental}

Figure 3 shows schematically the flame impingement setup. The experimental set up consists of two main structural components: the burner for heat generation and the heat receiver for heat absorption. In order to obtain a laminar one dimensional flame for different fuel air mixture velocities, two different burner types were used; a matrix flat burner surrounded by a water-cooled jacket was used for lower mixture velocities $(0.1 \mathrm{~m} / \mathrm{s}$ to $0.5 \mathrm{~m} / \mathrm{s})$ and a nozzle burner was used for a higher velocities $(0.7 \mathrm{~m} / \mathrm{s}$ to $1.2 \mathrm{~m} / \mathrm{s})$. The flames show cellular structures at higher flow rates on the matrix burner; whilst the nozzle burner cannot be used at lower velocities since the flame will stabilize inside the tube.

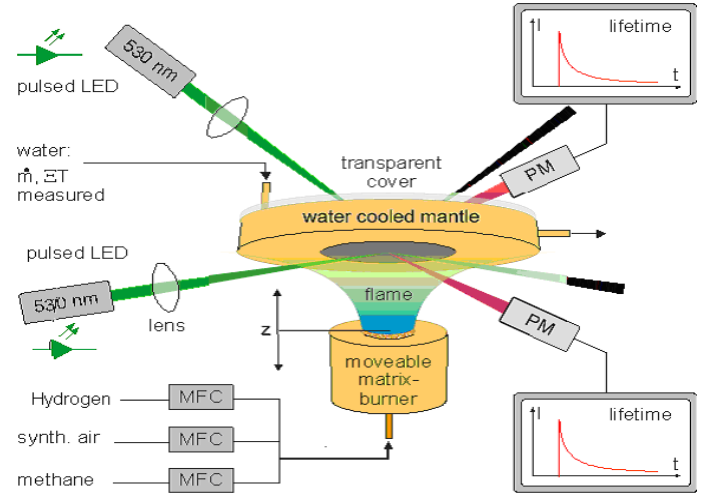

Figure 3: Experimental setup.

The heat receiver is made of a hollow water streamed disc of $30 \mathrm{~mm}$ thickness and $200 \mathrm{~mm}$ outer diameter. It has a brass ring as a frame for the ceramic plate on the flame side, and a transparent acrylic glass cover on the top. The temperature of the heated side of the plate was kept relatively low $(\mathrm{T}<500 \mathrm{~K})$ because the backside of the ceramic plate was in direct contact with the pressurized cooling water (ca. 3 bar). The ceramic plate is made of aluminium oxide $\left(\mathrm{Al}_{2} \mathrm{O}_{3}\right)$ of $6 \mathrm{~mm}$ thickness and $80 \mathrm{~mm}$ diameter and was coated on both sides with ruby as a phosphor.

For the temperature measurement on the flame side, the plate was irradiated with the $2^{\text {nd }}$ harmonic of a pulsed Nd:YAG laser $(532 \mathrm{~nm})$. The laser beam was aligned at the centre of the plate with a beam diameter of about $3 \mathrm{~mm}$. The cooled side phosphor coating was excited with a green LED array (Opto Technologies Inc., OTLH-0020-GN) with a peak wavelength at $525 \mathrm{~nm}$, emitting a typical power of $2.4 \mathrm{~W}$. Two photomultiplier (PM) tubes (Hamamatsu H6780-03) were used to receive the phosphorescence signals from both sides of the plate. The signal was recorded by a digital oscilloscope (Tektronix TDS 2024) and then transferred to a PC after typically averaging for 128 pulses. A fast pulse generator (Toellner, TOE7404) was used to provide the input for the 
green LED. The phosphorescence signal from both sides was recorded simultaneously, and each measurement was repeated three times in order to estimate the deviation. The average was taken for further evaluation.

Inlet and outlet temperatures of the cooling water, upper surface temperature of the ceramic plate, and the flat burner surface temperature were measured with platinum resistance thermometers (PT100) and thermocouples (K-type), respectively. The flow of the cooling water was kept constant $(20 \mathrm{~L} / \mathrm{h})$ for all experiments. Methane and hydrogen with $99.99 \%$ purity were used and burnt with synthetic air (volume $\%: 21 \% \quad \mathrm{O}_{2}$ and $79 \% \quad \mathrm{~N}_{2}$ ). The experiments were carried out for stoichiometric mixtures $(\varnothing=1)$ for the burner-to-plate distance of $15 \mathrm{~mm}$ with hydrogen contents of $10,25 \%, 50 \%$ and $75 \%$ of the methanehydrogen mixture.

\subsection{Modeling}

The stagnation-point flames were modeled as one-dimensional flows with detailed chemistry and transport processes using the Cantera code [27], where the similarity solution for the flow is implemented. The mechanism used was GRI 3.0 including 325 reactions of 53 species and the program solves the one dimensional balances for momentum, energy and species. Regarding the transport coefficients two models are implemented to Cantera: a mixture averaged model and a multispecies model. Calculations were performed using both, leading to similar results, so that the simpler mixture-averaged model results are presented here.

The temperatures at the burner surface and at the stagnation plate were provided as boundary conditions, while no surface reactions were included. Since it was found that changes within $20-40 \mathrm{~K}$ at the boundaries did not influence the results strongly, the burner surface temperature at $\mathrm{z}=0$ was fixed to $338 \mathrm{~K}$, in coincidence with a thermocouple measurement. The calculations were repeated for several stagnation surface temperatures, but again finding that the calculated heat flux rates were only weakly influenced by the exact value.

In order to obtain the heat flux from the model, the conductive heat flow to the surface had to be evaluated. For this one-dimensional system, the temperature gradient at the surface on the gas side had to be evaluated as well as the conductivity $(\mathrm{k})$ of the resulting gas mixture adjacent to the stagnation surface. Using Fourier's law for the gas phase:

$$
\dot{q}=k\left(\frac{d T}{d z}\right)_{g a s, z=\text { surface }}
$$

The gradient was evaluated from the temperatures of the final three grid points adjacent to the surface. A polynomial was calculated from them, and the slope at the surface was taken from the first derivative at the location of the surface. No radiative heat flux is included in the energy balance of the flame 
model, thus the heat flux may be underestimated. However, an estimation using the values from text books showed that the error should at most be in the area of a percent of the total calculated heat flux.

\section{Results and discussion}

\subsection{Surface temperature measurements}

Figures 4 shows a typical phosphorescence signal from the water cooled side, while two typical phosphorescence signals for the flame side of the stagnation plate are shown in Figure 5, as measured for the flame with $10 \% \mathrm{H}_{2}$ in the fuel and cold gas velocities of 0.1 and $0.5 \mathrm{~m} / \mathrm{s}$. The evaluated temperatures from the decay times are $343 \mathrm{~K}$ and $376 \mathrm{~K}$, respectively.

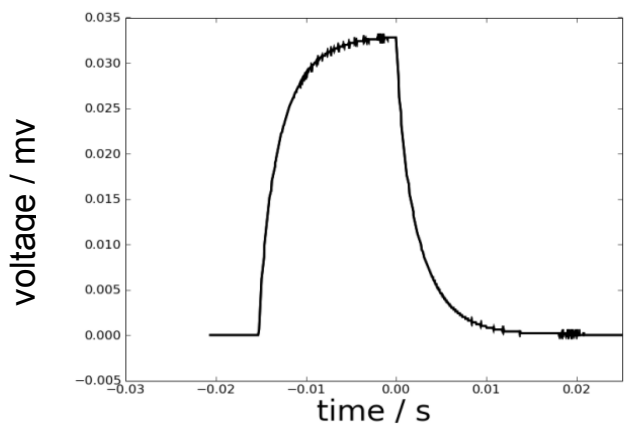

Figure 4: Phosphorescence signal from the cooled plate side using LED excitation.

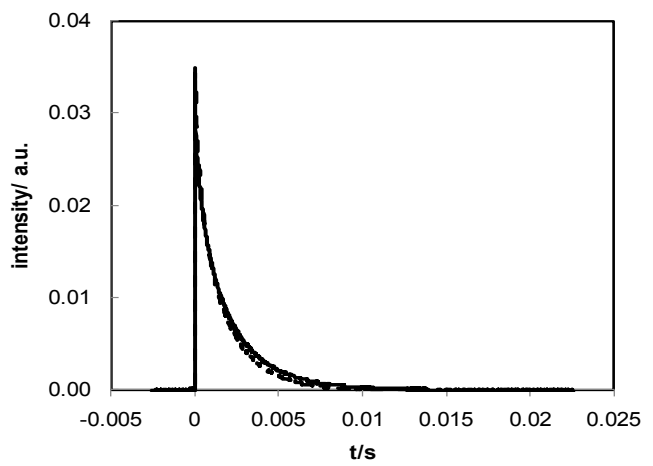

Figure 5: Typical phosphorescence signals after laser excitation for the flame heated plate side; both measured for the flame with $10 \%$ hydrogen in the fuel. The solid line was measured for a flow velocity of $0.1 \mathrm{~m} / \mathrm{s}$, the dotted line for $0.5 \mathrm{~m} / \mathrm{s}$. 
It is seen that a very good signal to noise ratio is obtained. However, in this relatively low temperature range an important disadvantage of the used ruby phosphor is also seen. Although the difference in lifetime is easily recognized, it is seen that the decay time varies only slightly with temperature in this low temperature range. The same information can in principle be obtained from the calibration curve of the phosphor, which has a relatively small temperature dependence in the temperature range between room temperature and $370 \mathrm{~K}$ and which is getting steeper between 370 and $500 \mathrm{~K}$. The observed scatter on repeat measurements was between $+/-2 \mathrm{~K}$ and $+/-6 \mathrm{~K}$, depending on the flame and temperature range.

Using the algorithm of Brübach et al. [25] for decay time evaluation lead to consistent decay time results.

Figure 6 shows the surface temperature measurement on the both sides of the ceramic plate for four different hydrogen-methane-air flames as a function of the total mass fluxes, all mixtures being stoichiometric. From the measured temperatures, only very small changes are recognized. The temperature levels rise with flow velocity, while the temperature difference between the flame heated front side and the water cooled back side also rises and remains in the order of $30-50 \mathrm{~K}$. The temperature levels are only slightly affected by the fuel mixture.

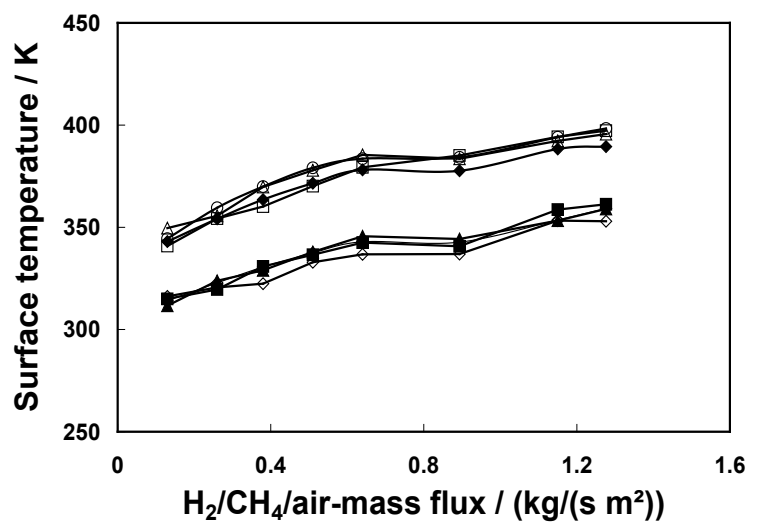

Figure 6: Surface temperatures measured for four different hydrogenmethane-fuel mixtures as a function of the mass flux. Triangles: $10 \% \mathrm{H} 2$, circles: $25 \% \mathrm{H} 2$, square: $50 \% \mathrm{H} 2$, diamonds: $75 \% \mathrm{H} 2$.

\subsection{The stagnation heat fluxes}

Based on the measured temperatures on both sides of the ceramic plate the heat flux density was calculated. Figure 7 shows the heat fluxes calculated for the four investigated stoichiometric hydrogen-methane flames. The heat fluxes were calculated using the average thermal conductivity of $\mathrm{Al}_{2} \mathrm{O}_{3}$ at the temperatures of the two ceramic plate sides. The value at room temperature of $22 \mathrm{~W} /(\mathrm{K} \mathrm{m})$ was 
taken as provided by the supplier. Since the absolute values of the published thermal conductivity of $\alpha$-alumina was found to vary by about $20 \%$ [28], we fear that this will be a main contribution to the absolute errors.

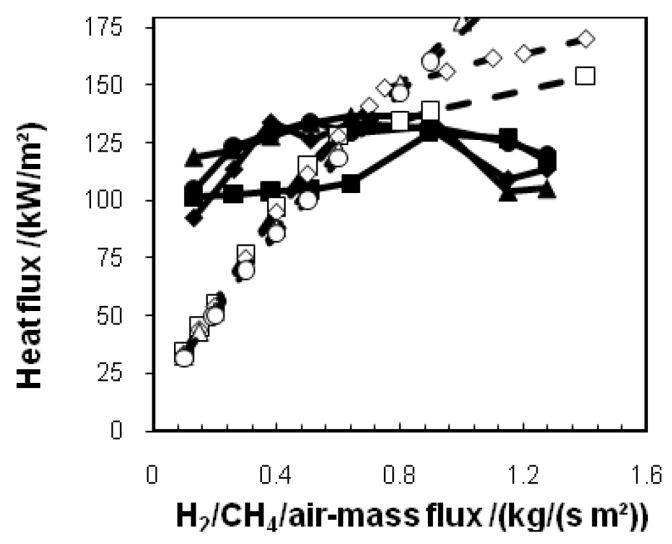

Figure 7: Measured (filled symbols) and calculated (open symbols) heat fluxes for four different fuel mixtures, as a function of mass flux rate. squares: $10 \% \mathrm{H} 2$, circles: $25 \% \mathrm{H} 2$, triangles: $50 \% \mathrm{H} 2$, diamonds: $75 \% \mathrm{H} 2$.

The heat fluxes for all four flames were quite similar if the experimental uncertainties are taken into account. The temperature difference of $30-50 \mathrm{~K}$ with uncertainties of $+/-4$ to $+/-12 \mathrm{~K}$ results in uncertainties of $20-40 \%$. Due to this, smaller deviations of the different curves will not be discussed. At the lowest flux of $0.13 \mathrm{~kg} /\left(\mathrm{m}^{2} \mathrm{~s}\right)$ the values range between 90 and $120 \mathrm{~kW} / \mathrm{m}^{2}$. The heat fluxes to the surface only vary slightly with the mass flux.

The modeling results are included in Figure 7. As can be seen, the model predicts only very small differences in the heat fluxes of the different flames at the low to moderate mass fluxes. However, an important difference between the modeled heat fluxes and the experimentally determined ones is also seen. A much stronger mass flux dependence of the heat fluxes is predicted than determined experimentally. In this burner stabilized regime, the increase in heat flux mainly comes from the reduction of heat losses to the burner with increasing flow velocity. Due to this, the model also predicts increasing flame temperatures until the flow velocity equals the free flame speed. In order to prove this model prediction, the (maximum) flame temperatures were studied by $\mathrm{OH}$ LIF thermometry, as described in the following.

\subsection{Flame temperature measurement}

Figure 8 shows the temperatures that were obtained using OH-LIF for four different flames as a function of the position in the flame. As can be seen, the flame temperature rises with increasing gas velocity from a maximum 
temperature of around $2000 \mathrm{~K}$ at $0.1 \mathrm{~m} / \mathrm{s}$ to $2460 \mathrm{~K}$ at $0.5 \mathrm{~m} / \mathrm{s}$. This is expected since the slower flames have a higher rate of heat transfer to the burner matrix. By the same token, the temperature gradient as the plate is approached also increases with increasing velocity. In contrast, the increase in hydrogen in the mixture (from $25 \%$ to $50 \%$ ) does not have a measurable effect on the flame temperature.

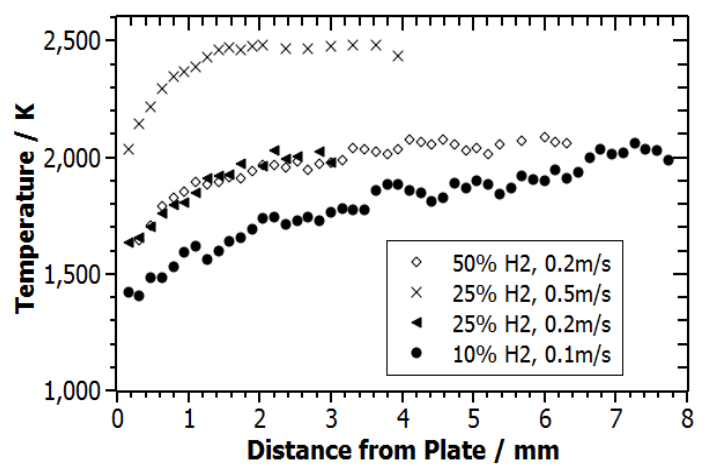

Figure 8: Flame temperature profiles obtained with OH-LIF.

The gradients could not be resolved for the investigated flames. This has a number of reasons. Firstly, the $\mathrm{OH}$ concentration rapidly drops with the temperature near the plate, resulting in a very poor signal from the OH-LIF. Further, the used optical setup only allows a resolution of about half a millimeter. Both reasons together lead to a bias in the measured temperatures near the plate, since the main $\mathrm{OH}$ signal in the excitation volume probably stems from the region most far away from the plate, preventing the measurement of correct temperature gradients. Especially the faster flames (higher cold gas velocity and/or higher concentration of hydrogen) have such steep gradients, where the temperature, according to modeling, drops from the maximum to the plate in less than a millimeter, that they could not be resolved here. However, the maximum temperatures are found to be present in a relatively large spatial range, so the measured maximum temperatures are shown in Figure 9 as a function of cold gas velocity and compared to the modeled results.

Firstly, it can be seen that the measured temperatures always lie a good $200 \mathrm{~K}$ above the simulated values. Only in the case of the $0.7 \mathrm{~m} / \mathrm{s}$ flames can this trend not be observed. It is likely that here the heat transfer to the nozzle burner, which is not included in the model and leads to horizontal heat losses, drastically reduces the actual flame temperature. Generally, the maximum temperature decreases as more hydrogen is added to the mixture. This is due to the fact that the hydrogen increases the free flame speed so that more heat is transferred to the burner at gas velocities below the free flame speed, thus reducing the maximum flame temperature. This trend changes at higher cold gas velocities. The slower flames with $10-25 \%$ hydrogen would become stabilized on the plate at around 
$0.6 \mathrm{~m} / \mathrm{s}$ flow velocity, shown by the kink in the modeled temperature profile. This effect can also be seen in the measurements at $1 \mathrm{~m} / \mathrm{s}$, where the $10 \%$ hydrogen flame is now around $100 \mathrm{~K}$ colder than the others. In the case of the $10 \%$ hydrogen flame, where most points have been measured, the modeled flame temperature follows the measured profile very well.

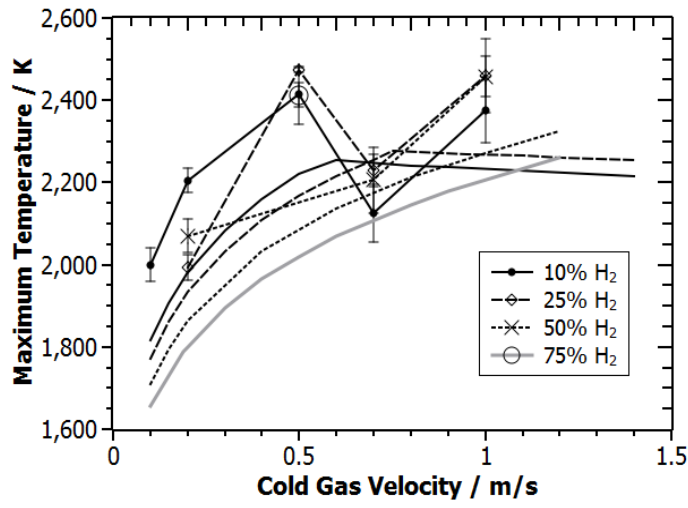

Figure 9: Maximum flame temperatures. Measured using OH-LIF (symbols with lines) and modelled (lines).

As it can be seen from the error bars of the measured temperatures, there is considerable uncertainty in some of the measurement. This could be improved by increasing the averaging, as was done for the $25 \%$ hydrogen flame at $0.5 \mathrm{~m} / \mathrm{s}$, where averaging was increased from 16 pictures to 64 pictures, reducing the statistical variation in the temperature from $\pm 70 \mathrm{~K}$ to $\pm 10 \mathrm{~K}$. However, this value only accounts for the statistical variation and not for the total error.

\subsection{Modeled OH mole fractions and temperatures}

In Figure 10, some selected temperature profiles and $\mathrm{OH}$ mole fraction profiles are shown from the model. All profiles are shown for the $10 \% \mathrm{H}_{2}$ flame. At a mass flux of $0.1 \mathrm{~kg} /\left(\mathrm{m}^{2} \mathrm{~s}\right)$ it is seen that the maximum temperature is lowest, and the temperature gradient at the stagnation surface at $0.015 \mathrm{~m}$ is also the smallest, leading to the smallest predicted heat flux of $34 \mathrm{~kW} / \mathrm{m}^{2}$. With increasing mass flux, the heat losses to the burner are reduced and the flame temperature approaches the adiabatic flame temperature. The $\mathrm{OH}$ mole fraction also increases with this trend. However, in direct vicinity of the surface the $\mathrm{OH}$ concentration is negligible.

For the two highest mass fluxes shown, the flow velocity is higher than the free flame speed and the flame is stabilized at the stagnation plate. The maximum temperatures are nearly the same and the temperature gradient near the surface only slightly depends on the mass flux, leading to similar heat fluxes of around $140 \mathrm{~kW} / \mathrm{m}^{2}$. 

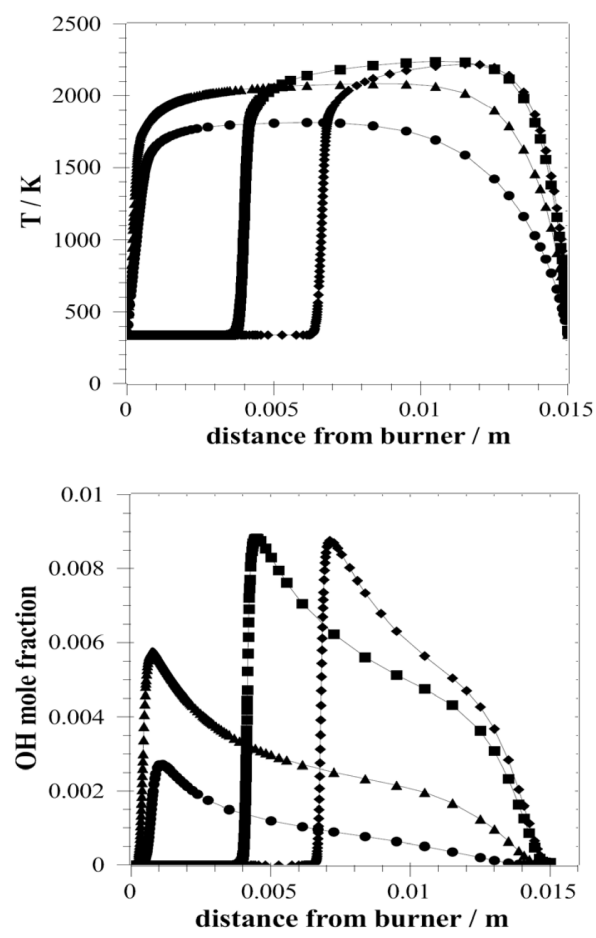

Figure 10: $\quad$ Modeled temperature and $\mathrm{OH}$ profiles for $10 \% \mathrm{H} 2 / \mathrm{CH} 4$ flames with four different mass fluxes (values in $\mathrm{kg} /(\mathrm{m} 2 \mathrm{~s})$ ): circles: 0.1 , triangles: 0.4 , squares: 0.8 , diamonds: 1.2 .

\section{Conclusions}

A new experimental setup was designed to measure the steady state surface temperatures of impinging premixed flames to walls, using thermographic phosphors. From the surface temperatures also the local heat fluxes were determined, an important parameter which is not too often investigated. So far, the experimental uncertainty is relatively large. This can be reduced in the future by using plates with higher thermal resistances. In addition, flame gas temperatures were measured using $\mathrm{OH}$ LIF. Both measurements show reasonable agreement with the modeling results, however further improvements are needed to have reliable tests for computational models.

\section{Acknowledgements}

The authors would like to thank Dr. Johannes Heinze for the LIF program that was used to fit the LIF spectra as well as the many hours of help and explanations regarding the $\mathrm{OH}$ LIF measurement. Also thanks to Pascalis 
Maggoutas for his competent support during the LIF measurements and the data evaluation. Generous financial support of parts of the present study by the Deutsche Forschungsgemeinschaft (DFG) is gratefully acknowledged.

\section{References}

[1] Chander, S. \& Ray, A., Influence of burner geometry on heat transfer characteristics of methane/air flame impinging on flat surface. Experimental Heat Transfer, 19, pp. 15-38, 2006.

[2] Dong, L. L, Cheung, C. S., \& Leung, C. W., Heat transfer characteristics of an impinging butane/air flame jet of low Reynolds number. Experimental Heat Transfer, 14, pp. 265-282, 2001.

[3] Dong, L. L., Cheung, C. S. \& Leung, C. W., Heat transfer from an impinging premixed butane/air slot flame jet. International Journal of Heat and Mass Transfer, 45, pp. 979-992, 2002.

[4] Milson, A. \& Chigier, N. A., Studies of methane and methane-air flames impinging on a cold plate. Combustion and Flame, 21, pp. 295-305, 1973.

[5] Rigby, J. R. \& Webb, B.W., An experimental investigation of diffusion flame jet impingement heat transfer. Proc. of the ASME/JSME Thermal Engineering Joint Conference, 3, pp. 117-126, 1995.

[6] Baukal, C. E. \& Gebhart, B., A review of flame impingement heat transfer studies. I: Experimental conditions. Combustion science and technology, 104, pp. 339-357, 1995.

[7] Baukal, C. E. \& Gebhart, B., A review of flame impingement heat transfer studies. II: Measurements. Combustion science and technology, 104, pp. 359-385, 1995.

[8] Viskanta, R., Heat transfer to impinging isothermal gas and flame jets. Experimental Thermal and Fluid Science, 6, pp. 111-134, 1993.

[9] Viskanta, R., Convective and radiative flame jet impingement heat transfer. International Journal of Transport Phenomena, 1, pp. 1-15, 1998.

[10] Chander, S. \& Ray, A., Flame impingement heat transfer: a review. Energy Conversion and Management, 46, pp. 2803-2837, 2005.

[11] Remie, M. J., Cremers, M. F. G., Schreel, K. \& de Goey, L. P. H., Analysis of the heat transfer of an impinging laminar flame jet. International Journal of Heat and Mass Transfer, 50, pp. 2816-2827, 2007.

[12] Remie, M. J., Cremers, M. F. G., Schreel, K. \& de Goey, L. P. H., Flame jet properties of Bunsen-type flames. Combustion and Flame, 147, pp. 163-170, 2006.

[13] Kleijn, C.R., Heat transfer from laminar impinging methane/air flames. Computational Technologies for Fluid/Thermal/Structural/Chemical Systems with Industrial Applications, pp. 259-269, 2005.

[14] Poinsot, T., Echekki, T. \& Mungal, M., A study of the laminar flame tip and implications for turbulent premixed combustion. Combust. Sci. Technol, 81, pp. 45-73, 1992.

[15] Tian, K. Z., Li, S., Staude, S., Li, B., Sun, Z. W., Lantz, A., Aldén, M. \& Atakan, B., Influence of ferrocene addition to a laminar premixed propene 
flame: Laser diagnostics, mass spectrometry and numerical simulations. Proceedings of the Combustion Institute, 32, pp. 445-452, 2009.

[16] Hartlieb, A. T., Atakan, B. \& Kohse-Höinghaus, K., Temperature measurement in fuel-rich non-sooting low-pressure hydrocarbon flames. Applied Physics B: Lasers and Optics, 70, pp. 435-445, 2000.

[17] Allison, S. W. \& Gillies, G. T., Remote thermometry with thermographic phosphors: instrumentation and applications. Review of Scientific Instruments, 68, pp. 2615-2650, 1997.

[18] Atakan, B., Eckert, C. \& Pflitsch, C., LED excited Cr3+: Al2O3as thermographic phosphor. Measurement Science and Technology, 20, p. 075304, 2009.

[19] Brübach, J., Dreizler, A. \& Janicka, J., Gas compositional and pressure effects on thermographic phosphor thermometry. Measurement Science and Technology, 18, pp. 764-770, 2007.

[20] Brübach, J., Zetterberg, J., Omrane, A., Li, Z. S., Aldén, M. \& Dreizler, A., Determination of surface normal temperature gradients using thermographic phosphors and filtered Rayleigh scattering. Applied Physics B: Lasers and Optics, 84, pp. 537-541, 2006.

[21] Feist, J. P., Heyes, A. L., Choy K. L. \& Su, B., Phosphor thermometry for high temperature gas turbine applications. International Congress in Instrumentation in Aerospace Simulation Facilities. p. 6, 1999.

[22] Khalid, A. H. \& Kontis, K., Thermographic Phosphors for High Temperature Measurements: Principles, Current State of the Art and Recent Applications. Sensors, 8, pp. 5673-5744, 2008.

[23] Seyfried, H., Richter, M., Alden, M. \& Schmidt, H., Laser-induced phosphorescence for surface thermometry in the afterburner of an aircraft engine. AIAA Journal, 45, pp. 2966-2971, Dec 2007.

[24] Pflitsch, C., Siddiqui, R. A. \& Atakan, B., Phosphorescence properties of sol-gel derived ruby measured as functions of temperature and $\mathrm{Cr} 3+$ content. Applied Physics A: Materials Science \& Processing, 90, pp. 527-532, 2008.

[25] Brübach, J., Janicka, J. \& Dreizler, A., An algorithm for the characterisation of multi-exponential decay curves. Optics and Lasers in Engineering, 47, pp. 75-79, 2009.

[26] Atakan, B., Heinze, J. \& Meier, U. E., OH laser-induced fluorescence at high pressures: spectroscopic and two-dimensional measurements exciting the A-X $(1,0)$ transition. Applied Physics B: Lasers and Optics, 64, pp. 585-591, 1997.

[27] Goodwin, D. G., An open-source, extensible software suite for CVD process simulation. Chemical Vapor Deposition XVI and EUROCVD, 14, pp. 2003-08, 2003.

[28] Hemrick, J. G., Kistler, C. W., Wereszczak, A. A. \& Ferber, M. K., Thermal conductivity of alumina measured with three techniques. Journal of testing and evaluation, 31, pp. 438-442, 2003. 